\title{
COMPETENCIES AND QUALIFICATIONS IN OUTDOOR EDUCATION
}

\author{
PAULINA KIDA \\ Faculty of Pedagogy, University of Wrocław \\ ul. J. W. Dawida 1, Wrocław, Poland \\ E-mail address: paulinakida@gmail.com \\ ORCID: 0000-0003-1424-9782
}

\begin{abstract}
Aim. A synthesis of different researches on outcomes in adventure and outdoor education was used in this paper in order to develop a universal tool, aiming to support analyses of future groundwork materials in competences researches.

Method. The article is based on an extended literature review. The research becomes more multiplying than comparative in nature or serves to deepen or add knowledge about outcomes in adventure outdoor education.

Results. In this theoretical reasoning, attempt of selection, classification, the connection within broader categories of competences was made by reviewing previous researches and literature; moreover, it was tested on examples of the concrete educational process.

Conclusion. In reviewed literature researchers often use tools designed particularly to serve this purpose and and aimed at structuring the skills and competencies acquired by participants in this kind of education. Researchers dealing with this topic are likely to experience difficulty while trying to summarize and compare the results of other studies presented in literature due to the various classifications and terminology used.

Key words: outdoor education, adventure education, competencies, qualifications.
\end{abstract}

\section{INTRODUCTION TO ADVENTURE OUTDOOR EDUCATION}

$\mathrm{T}$

he outdoor and adventure education method is a contemporary proposal

for education through a universal teaching model that is based on universal rules, regardless of the place in the world, culture or age, and in accordance with which a student should learn to read meanings through experience. It takes from numerous known and long respected methods used in such activities as scouting. Robert Baden-Powell was considered to be the father of this movement in Great Britain, Ernest Thompson Seton in the US, and Andrzej Małkowski in Poland.

Outdoor Education is a way to achieve educational objectives through managing the direct experience in an outdoor environment with the use of 
tools provided by this environment as teaching aids. This is a combination of experiencing in learning about the environment - our surroundings, with subjects and activities connected to nature (Miles, \& Priest, 1990) which occur simultaneously. In their study for the European Institute for Outdoor Adventure Education, Pate Higgins and Chris Loynes, other researchers studying the Outdoor Education problems determined features distinguishing this teaching method from others. Mentioned researchers acknowledged that, firstly, the outdoor teaching model boosts personal and social development; secondly, the activity understood as an outdoor activity is not recreational, but an educational process. That process is fulfilled as an inner journey and discovering new lands, not only from the geographical point of view but also from discovering inner potential. The third feature legitimizing the outdoor education model is a direct experience method that replaces the transmission model of teaching. The fourth component of the outdoor education model is respect for nature by developing a Scandinavian concept of "friluftsliv," which means feeling at home in nature (Gelter, 2000). Fifthly, students should be subject to partial responsibility for the educational process. Thus, the teaching and learning process is not aimed at passing an exam or getting a grade but realizing that consistency and responsibility for one's actions is the only key to be successful in a life-long perspective (Miles, \& Priest, 1990). The definition of Adventure Education by Scott Wurdinger indicates its three components: enhancing the educational process by experience, developing moral values, and developing readiness to take risks (Rubens, 1997). For John Miles and Simon Priest, who are the contemporary mentors of Adventure Education, this is a deliberately planned and conducted educational process including a risk element. William Putman defines adventure as an experience whose result, in principle, contains an element of uncertainty, where an education element is understood as a process of cognitive, moral and social development during the acquisition of knowledge, skills, and experience (Miles, \& Priest, 1990).

The Outdoor and Adventure Education methods glorify direct experience laced with strong emotions during which students expand their comfort zones and become more ready to take up new challenges and are open to pioneering ideas. In research review and literature experiential, adventure and outdoor education are used interchangeably and as equivalents. Similarly, for the purpose of this paper, they will be contained in one common notion Adventure Outdoor Education or AOE.

\section{COMPETENCE AND SKILLS IN AOE}

Literature sources provide a comprehensive description of what is included within the notions of skills, competencies or results as understood by the objectives achieved during the teaching and learning process in general, and as they are perceived by general didactic rules. Therefore, skills and results acquired in AOE are so distinctive among other movements that it is difficult to explicitly 
define the characteristics of this method from a general theoretical standpoint. AOE theory field seems to be narrow and specialized, but contains a wide range of educational aspects. Generally, developing outdoor skills in AOE is beneficial on its own and, additionally, opens the way to other opportunities (Ewert, \& Siprhorp, 2014). This definition, which seems to have a very broad meaning, reflects the main feature of AOE outcomes - they pertain to each category of skills and competencies and are dependent on the involvement and accepting responsibility for the teaching and learning process by AOE education participants. They are holistic in nature, flexible and transferable to everyday life. On the other hand, those who do not distinguish between AOE and recreation see the AOE outcomes only as technical outdoor skills.

Technical skills are an indispensable base for learning other lessons in many AOE programs.

Participants with good backpacking and navigation skills are able to connect with nature in order to foster their personal reflection. Other skills, as for example teamwork or leadership skills can be developed by sailing a 45 -foot boat. A backcountry classroom, which is unpredictable in nature, gives students lots of opportunities to make decisions and overcome challenges. Thus, the development of technical outdoor skills, which are often considered as a critical outcome of AOE programs, is the base for numerous interpersonal and intrapersonal outcomes (Ewert, \& Siprhorp, 2014). For teachers and students without a teaching theory background, the AOE classroom is understood as just another chance for fun and entertainment, but also an additional educational opportunity. AOE education assumes that the achievement of social competences, gaining knowledge and motor skills should be secondary to an outdoor classroom and that this kind of classroom is not an end itself. As a result, AOE only presents opportunities for participants to achieve the assumed outcomes, which are personal growth and development, and not to create them. It is up to participants what they take away from a program apart from what it provides - they choose what to process and learn from it, whether consciously or subconsciously (Ewert, \& Siprhorp, 2014). One of the rules of adventure education, or rather a mere adventure, is that at the beginning its result is unpredictable. The same goes for education with an element of adventure and its integrated risk where outcomes are also verified during its course; they are only partially planned and mostly dependent on needs but also on participants' input. AOE methods work with personal and group resources, from which they obtain new skills and competencies.

A talented teacher or trainer leads a group and all participants individually through a planned process, however they work with a potential presented by each group and each participant within this one special educational situation in which they are set. However, these skills and competencies are not in limbo. Educators and teachers working with $\mathrm{AOE}$ independently, with different programs, beneficiaries, and countries share similar experiences about outcomes, which is noticeable particularly in the above-presented resources. 


\section{OUTCOMES IN AOE IN THE RESEARCH REVIEW}

In the process of searching structure and categories for competences gained within AOE, the general taxonomy of educational objectives can be used as in general teaching. Bloom's most common taxonomy of educational objectives can be adapted for $\mathrm{AOE}$ results, as the natural consequences of its objectives.

This situation looks parallel in educational actions conducted within outdoor adventure education methods. Given their specificity and holistic nature, outcomes should be found and classified within more than just cognitive categories of competencies and skills. Learning outcomes include cognitive, skill-based and affective outcomes (Kraiger, Ford, \& Salas, 1993; Bloom, Engelhart, Furst, Hill, \& Krathwohl, 1956). Cognitive outcomes can be divided into quantity and type of knowledge, such as: declarative, procedural and conditional. And skill-based outcomes can be seen in performing the process or procedures. Cognitive knowledge is e.g. explaining how to locate your position in the backcountry or finding your way is a skill-based outcome. And last but not least, affective outcomes are dependent on a person and an example of confidence is one's ability to travel in the backcountry or a will to start an outdoor adventure. Thus affective outcomes are various for different individuals and include motives, attitudes, self-perceptions, feelings (Ewert, \& Siprhorp, 2014). Although this taxonomy is one of the simplest and often considered as archaic, it should be appreciated due to its holistic view on the educational process which is not limited only to the cognitive area. AOE is a mix of knowledge, emotions and works with one's body; it involves the brain, heart, and the whole body physically. As a result, outcomes are achieved evenly within various development areas of a person.

Separation of these three components from one another disables the interiorization of the gained skills and competencies. Any educational experience involves a combination of cognitive, skill-based, and affective outcomes. Even if you know what altitude and longitude are but you cannot travel to the backcountry or do not have the motivation to try to route findings, this is of little practical use. Similarly, when you are strongly motivated but have no or little knowledge, you can find yourself in trouble. AOE programs are holistic and multi-domain in nature (Ewert, \& Siprhorp, 2014). AOE does not use subjects or thematic blocks, but it is a complex educational concept. Despite the fact that it is very practical, it is used to gain theoretical knowledge due to numerous sociometric methods, active review, debriefing or individual sessions with teachers or instructors, and it is also a unique opportunity to develop one's volition. AOE outcomes have been studied by many researchers. To identify common areas, repetitive skills, and competencies, it is worth looking closer at categories of skills and competencies that researchers extracted independently from one another.

Ritson says that in AOE education you are not able to separate what is a planned objective of a particular program from what is a hidden educational objective, which consists of a unique combination of people, their experience, 
circumstances, and values worshiped in a particular group you work with. Very often the main focus of the adventure learning programs is either the formal or informal aspect of learning but, actually, they both appear simultaneously. Adventure outcomes can be divided into formal, which are: skill development, achievement of adventure qualifications, contributory factors while achieving outcomes in other situations or environments, such as school examiners, and informal, such as becoming more self-aware, learning how to work with others, developing leadership or team skills (Ritson, 2016). Adventurous activities naturally help participants develop skills in the activity itself, which builds accreditation into a program or helps to relate skills gained in the activity to this activity and its fields. The nature of adventurous activities makes participants cooperate and make decisions, thus any program includes informal learning. The division of competences into formal and informal indicates that they are based on feedback and do not work autonomously, recalls a well-known distinction into soft and hard, and measurable and non-measurable skills. However, this is not a decisive criterion that clearly orders all skills and competencies, especially when we look closer at numerous and various informal competencies. They need to be further categorized and classified.

Adventure learning outcomes can also be tangible or intangible. Tangible outcomes include formal accreditations and qualifications as well as other certification gained by participants, and they may be gained in the form of national adventure body awards or in school. Intangible outcomes include personal traits gained in the course of education and come from engagement and achievement, such as confidence, self-esteem, self-awareness, tolerance and social learning (Ritson, 2016). The concept of tangible and intangible outcomes leads us to a product or a process curriculum - a notion analyzed earlier. A product curriculum is a source of hard outcomes that can be easily measured during examinations or recitation of facts and figures to a certain standard and in a prescribed manner. The result of a process curriculum is constructed by soft outcomes that are difficult to measure or evidence because of the fact that they are specific to each individual; these developmental changes often go unnoticed for long periods as they appear when an individual matures. But both hard and soft outcomes are critical for human development and learning. This perspective proves a certain tendency to consider soft skills as difficult to measure, which stopped being a problem in the humanities. Together with the development of qualitative studies within this field studying soft skills and skills that might be difficult to measure is not a problem anymore, assuming that the used tools are correctly chosen and the study is based on source literature.

Other examples of studies show a multiplicity of categories but also a regular repetitiveness related to sheer skills and competencies. A comprehensive meta-analysis conducted by Hattie, Marsh, Neil, and Richards in 1997 has been one of the most comprehensive studies of the AOE outcomes so far. They analyzed 96 reports, papers, and studies that involved 151 samples. As a result, they found 40 outcomes that they classified into six broad categories: academic, leadership, self-concept, personality, interpersonal and adventuresome. Other 
researchers dealing with the same problem found similar results. A 1998 study conducted in three national wilderness education programs that included 450 participants found that the often repeated outcomes were personal, intellectual and behavioural in nature (Kellert, 1998). Some of the more common outcomes included the following: interest and participation in outdoor activities, connection to nature, both active and spiritual, self-confidence and self-esteem, problem-solving skills, autonomy and independence, initiative, interpersonal relationships, career choices.

In 2002, the Association of Experiential Education carried out a survey among their members regarding the targeted program outcomes. The 39 outcomes that emerged in this study were split into four major categories: professional development, therapeutic, cognitive and personal development (Norling, \& Sibthorp, 2006). The most commonly reported by AOE programs' members outcomes were: targeting cognitive and personal development. The cognitive outcomes included: skill building, environmental education, and academic development. The personal development category included: self-esteem, self-determination, and self-awareness.

In 2007, Sibthorp and colleagues carried out a survey among a random sample of the National Outdoor Leadership School graduates to learn which lessons from their courses turned out to be most useful in their everyday lives (Sibthorp, Pisley, Furman, \& Gookin, 2008).

The investigated transferable outcomes included: outdoor skills, changes in life perspective, appreciation for nature, self-confidence, ability to serve as a leader, self-awareness, ability to work as a team member (Sibthorp, 2011). In more recent research that was conducted for several years, the team tracked participants of NOLS and Outward Bound. The participants regularly reported values of the following AOE outcomes: relationship with others, self-awareness, enjoyment of life, sense of accomplishment, self-fulfillment, self-esteem, and self-confidence (Goldenberg, Soule, Cummings, \& Pronsolino, 2010). This outcome category is very significant as it shows that AOE acquired competencies and skills are meant to be deeply internalized and to serve as ones that graduates of AOE programs use every day in their school, professional and family lives.

As AOE programs were created for a wide range of purposes, contexts, and designs, they target significantly various outcomes, attract various populations and provide various experiences. Thus we can expect many different outcomes from a week-long corporate team-building sea kayaking program in Alaska and from an environmentally focused backpacking trip of young people to the Adirondacks. The same applies to therapeutic programs for people addicted to substances, to programs targeted at disabled, or programs working alongside schools to support the science curriculum and academic mission (Ewert, \& Siprhorp, 2014). This means that it is impossible to create a comprehensive range of outcomes within one tool as there are factors like the general objective, program recipients group profile, context, site, time and others that will make each of these educational opportunities a unique, personal and incomparable 
experience. Qualitative studies assume that this situation is the starting point on a paradigm level. Hence, it is worth continuing to search for common categories to describe these competencies. However, with the consideration of these exceptional circumstances that accompany the implementation of each AOE program.

The AOE program outcomes can be divided into: initial, intermediate, and long-term outcomes. An example of an initial outcome temporarily and contextually tied to experience is an improved mood after a peak ascent. Intermediate outcomes are for example, higher self-esteem after a successful climb or improved teamwork after a small-group expedition. These outcomes evolve slower, but they are more stable. The intermediate outcomes can be split into interpersonal and intrapersonal outcomes. The first group covers teamwork, leadership, communication skills, and group cohesion, while the latter involves self-construct (e.g. self-confidence, self-concept), values (connection to nature, spirituality), cognitive and physical skills (problem-solving skills), or mental states (mood). The last category - long-term outcomes - is difficult to directly connect to AOE experiences. Nevertheless, the research literature shows that many intermediate outcomes are directly linked to long-term outcomes. Intermediate outcomes, which are highly valued in the workplace include teamwork, communication skills, and leadership. Long-term outcomes that evolve from these intermediate outcomes are school and work performance, psychological well-being, quality of life, active lifestyle, physical, spiritual, and mental health (Ewert, \& Siprhorp, 2014). The time approach to outcomes where participants can observe them on their own is interesting especially because of the value of these skills and competencies which affect the future benefits of participation in AOE programs.

Actually, AOE programs' outcomes cannot be universally classified because many of the existing programs and classification schemes overlap within the domains. There are more potential divisions of outcome classes than those already mentioned, e.g. psychological, sociological, educational, and physical (Ewert, 1989) as well as: cognitive, affective, social and interpersonal, physical and behavioural (Rickinson, Dillon, Teamey, Morris, Choi, Sanders, \& Benefield, 2004)

In light of the studies and category analyses of outcomes referred to above, certain conclusions can be drawn. Some categories, as well as detailed skills and competencies, are repeated in subsequent studies, which indicate some tendencies in the studies, or even more, so that AOE is effective in holistic human development. Another conclusion from the research review analysis is that despite the fact that the occurrence of different categories is helpful for various studies (e.g. such factors as time and range, inter- and intra- qualities), incorporating all proposals into one study would make it ambiguous and doubtful on the level of the theoretical assumptions, and some outcomes would be repeated. For example, analyzing outdoor skills (climbing, kayaking, running, survival skills, etc.), they may be considered in different categories (cognitive, psychomotor, short- and long-term, measurable and non-measurable) and the same outcome can be put in multiple categories and unquestioningly repeated. There is a serious risk that the outcome analysis would conclude as technical considerations rather than as substantive ones. 


\section{CATEGORIZATION AND SYSTEMATIZATION OF AOE OUTCOMES}

All categories and examples of skills and competencies acquired by AOE participants mentioned above will be now treated as a market of categories and examples that can be gained as AOE outcomes. The next step will be an attempt to include them in the general categories. This is an attempt to design a tool for uniform description and presentation of results of studies on AOE outcomes.

Various researchers used different categories in their studies, or different terminology to name competences and skills, however, these categories often coincide and cover repetitive content, such as flexibility and openness to new ideas, or psychological well-being and satisfaction. Hence, some examples have been neglected not to multiple descriptions of the same outcomes and others have been added to provide a fuller picture of what is included in a given category. The following table, which is a summary and classification of AOE outcomes, is the result of the own work of the author of this paper, based on research and literature review, who was involved with categories but still inspired by the tools used by other researchers.

Table 1. Outcomes in Outdoor Adventure Education

\begin{tabular}{ll}
\hline & \multicolumn{1}{c}{$\begin{array}{c}\text { FORMAL OUTCOMES: } \\
\text { (hard and metacognitive skills) }\end{array}$} \\
\hline outcome type & explanation and examples \\
\hline $\begin{array}{l}\text { declarative } \\
\text { knowledge }\end{array}$ & $\begin{array}{l}\text { spoken or written factual information (e.g. scientific theories), } \\
\text { theoretical knowledge gained during learning, training, workshops, } \\
\text { and official educational process; exams, certificates, licenses, the use } \\
\text { of foreign languages, the naming of outdoor equipment; }\end{array}$ \\
\hline $\begin{array}{l}\text { procedural } \\
\text { knowledge }\end{array}$ & $\begin{array}{l}\text { know-how, understanding rules, activities, their sequence (e.g. } \\
\text { teaching safety rules and conducting classes in a ropes course, rules } \\
\text { of conducting review and debriefing); }\end{array}$ \\
\hline $\begin{array}{l}\text { conditional } \\
\text { knowledge }\end{array}$ & $\begin{array}{l}\text { knowledge about when to use this procedure, when they work; } \\
\text { (soft, psychomotor, and affective skills) }\end{array}$ \\
\hline type & $\begin{array}{l}\text { explanation and examples } \\
\text { Intrapersonal } \\
\text { skills }\end{array}$ \\
$\begin{array}{l}\text { self-development and attitudes: motives, self-perception, personal } \\
\text { awareness, self-confidence, self-esteem, self-awareness, autonomy } \\
\text { and independence, initiative, interest in exploration, responsibility, } \\
\text { attitudes, overcoming own limitations (being overweight, physical } \\
\text { fitness, language barrier, working with someone younger, older, from } \\
\text { different cultural background etc.), flexibility, openness to new ideas; } \\
\text { values and feelings: an active and spiritual connection with nature, } \\
\text { appreciation for nature such as leave no trace principles, enjoyment } \\
\text { of life, sense of accomplishment, adventurousness, tolerance, mental } \\
\text { states - such as mood, cultural values, place and space perception, } \\
\text { satisfaction, autonomy, emotional control; }\end{array}$ \\
\hline
\end{tabular}




\begin{tabular}{|c|c|}
\hline $\begin{array}{l}\text { Interpersonal } \\
\text { skills } \\
-\quad \text { on partici- } \\
\text { pants level }\end{array}$ & $\begin{array}{l}\text { social learning that comes from engagement and achievement on a } \\
\text { participant level: organisational competence, ability to work as a team } \\
\text { member, ability to work as a leader, relationship with others, friendship, } \\
\text { taking responsibility for one's own learning, for group, for structures } \\
\text { (e.g. low rope, tree house, belaying during climbing etc.); }\end{array}$ \\
\hline $\begin{array}{l}\text { Interpersonal } \\
\text { skills } \\
\text { - on group } \\
\quad \text { level }\end{array}$ & $\begin{array}{l}\text { social learning that comes from engagement and achievement on } \\
\text { a group level: group cooperation, interpersonal relationships, } \\
\text { communication with others (style of communication, non-violent } \\
\text { communication etc.), group decision-making, learning to work with } \\
\text { others, developing team skills, problem-solving skills; }\end{array}$ \\
\hline Practical skills & $\begin{array}{l}\text { outdoor skills: camp connectedness, knotting, using rope, preparing } \\
\text { a shopping list, cooking in the field, responsible packing, navigation } \\
\text { skills, being outdoors during all types of weather, setting up a fire, } \\
\text { cleaning sites, dishes, taking a shower outdoors, sleeping outdoors, } \\
\text { being at high altitudes (e.g. in the mountains), being low (e.g. in } \\
\text { a cave), climbing, kayaking, biking, hiking, swimming, making } \\
\text { additional things like an outdoor sauna, playing the guitar, ukulele, } \\
\text { singing, removing ticks; }\end{array}$ \\
\hline $\begin{array}{l}\text { Skills transfer- } \\
\text { able to future } \\
\text { long-term } \\
\text { outcomes }\end{array}$ & $\begin{array}{l}\text { changes in life perspective like school and work performance, } \\
\text { psychological well-being, quality of life, active lifestyle, physical, } \\
\text { spiritual and mental health, career choices. }\end{array}$ \\
\hline
\end{tabular}

The last stage is an attempt to present the application of this tool on a 10-day training "Train of Trainers" that was organized by the Outward Bound in Romania at the turn of July and August 2017.

Below is a summary of the ToT program outcomes elaborated on the basis of the author's own experience evolved during the training, and visual materials collected during the training. The table is the composition of research review summary and examples of own practical experiences, inspired by autobiography methodology, with the usage of collected photos, notes about own process, in order to try out this tool before it will be implemented in own researches.

Within formal outcomes (hard and metacognitive skills) distinguished among above-presented types, there are following examples of outcomes.

For declarative knowledge:

- Outward Bound Romania theoretical exam with participation of the ministry of sports officials; practical exam consisting in developing 2-hour classes, including debriefing and assessment by a group and Outward Bound trainers, conducting the classes with a group as a trainer;

- opportunity to pass a theoretical and practical exam authorizing the issuance of a certificate AOE theories,

- general introduction to experiential education and adventure education,

- general Outward Bound information (history, main values),

- main goals of the training,

- theories such as: the Comfort Zone Model, the Challenge by Choice Principle, the Kolb's cycle (Experiential Learning Cycle), the Funneling Model 
of Experiences, efficient and effective debriefing, reviewing methods, feedback rules, leadership styles, John Adair's Leadership model, Solution Focused problem solving, Iceberg model, Jo-Harry Window, Maslow Pyramid,

- group processes elements: Group Dynamics, Risk Assessment, things to improve as an outdoor trainer according to the meta-debriefing conclusion, Learning Styles,

- Outdoor Trainer skills.

For procedural knowledge:

- adjusting activities to the group dynamics,

- conducting games in low and high ropes courses (teaching safety and assurance rules),

- preparing a mountain expedition (planning what equipment to take, catering, sleeping, knowledge of risk e.g. while meeting a large group of bears),

- adjusting methods, conducting a review, debriefing, and receiving and giving constructive feedback.

For conditional knowledge:

- adjusting the program to the needs and capabilities of the group,

- recognizing the strong and weak sides of the group and adjusting the level of a challenge within the learning rather than the comfort or panic zone,

- knowing when to modify challenges, change rules during a game without disturbing the group and group processes,

- evaluating the effectiveness of the program and specific actions, and modifying them during the course of these actions.

Within informal outcomes (soft, psychomotor, and affective skills), I discovered several outcomes divided by types of skills.

Intrapersonal skills (self-development and attitudes, values and feelings):

- motives (long-distance hiking, keeping night watch and fire, making a personal challenge, learning to the exam),

- personal awareness (presenting own ideas to the group, decide which part of the expedition you want to be responsible for - like navigation, cooking, equipment, risk management),

- self-esteem (no judgment by trainers site about the tasks and results),

- autonomy and independence (the possibility of refusing to participate in any activity, talking about your individual needs, defending your opinion, feelings, dignity, avoiding conflicts),

- initiative (proposing solutions, initiating morning games and conducting them on their own, organizing free time, making laundry, learning together, sharing materials for learning and after the project - photo exchange, literature, networking),

- interest in exploration (taking part in activities - getting to know the area after hours of organized activities, reading additional literature, talking with trainers, sharing experiences from other training and workshops), 
- responsibility (self-packaging of things needed for living in the forest, but also organization of the camp for the whole group, active participation in learning, suggesting known theories and their explanation to the group, shopping, hiking route planning according to the group's possibilities, planning stops, meals, purchase costs, responsibility for not leaving traces in accordance with the rules of no leave trace idea),

- attitudes (dynamic reaction in relation to onerself and to the group - going to the front or leaving space for the less daring participants, fair-play behaviour, openness to the other's needs, humility towards their weaknesses),

- overcoming own limitations (being overweight, physical fitness, language barrier, working with someone younger, older, from different cultural background, etc.),

- flexibility (the ability to give up your plan for other ideas to give up, openness to new ideas)

- social learning that comes from engagement and achievement on a group level,

- group cooperation (group contract, preparation of the plan and participation in the expedition without active participation of trainers, group games - especially in a high rope park, common tactics and strategy during games, sharing opinion during debriefings, organization of the practical side of the trip - common laundry, cooking, during the expedition: building a shelter, changes during the night watch),

- interpersonal relationships (negotiating rules, negotiating common solutions, showing understanding, patience, talking about needs, feelings, showing friendships, support, resistance, group decision-making),

- communication with others (style of communication, non-violent communication, etc.),

- learning to work with others,

- developing team skills,

- problem-solving skills.

Interpersonal skills:

Social learning that comes from engagement and achievement on a participant level:

- organizational competence,

- ability to work as a team member,

- ability to work as a leader,

- relationship with others,

- friendship,

- taking responsibility for one's own learning,

- for the group, for structures (e.g. low rope, tree house, belaying during climbing, etc.),

Social learning that comes from engagement and achievement on a group level:

- group cooperation,

- interpersonal relationships, communication with others (style of commu- 
nication, non-violent communication, etc.),

- group decision-making,

- learning to work with others,

- developing team skills,

- problem-solving skills.

Practical skills (outdoor skills):

- camp connectedness,

- knotting, using rope,

- preparing a shopping list,

- cooking in the field,

- responsible packing,

- navigation skills,

- being outdoors during all types of weather,

- setting up a fire,

- washing dishes,

- sleeping outdoors,

- being at high altitudes (e.g. in the mountains), being low (e.g. in a cave),

- climbing, biking, hiking,

- making additional things like an outdoor sauna, playing the guitar, ukulele, singing,

- removing ticks.

Skills transferable to future (Long-term outcomes):

- changes in life perspective such as school and work performance (debriefing methods, which participants try to find in their current professional position and school situation, in which they can apply new attitudes and skills),

- psychological well-being,

- quality of life,

- physical, spiritual and mental health (physical activities that can become a ritual - morning yoga, running, experience acquired in mountain-like hiking, ability to organize hiking in private life, and the test that one can physically experience this adventure makes everyday life more eager, we make a physical effort with less intensity than at the workshops, frequent exits from the comfort zone, make it wider),

- career choices (considering changes, learning new career paths, awareness of your strengths and weaknesses, ability to set goals on the way and achieve them).

\section{CONCLUSIONS}

In the light of the studies and numerous researches referred to in this paper, one can consider many $\mathrm{AOE}$ outcome categories into which researchers tried to enclose competences and skills gained by AOE programs' participants, or other educational opportunities and training carried out in the AOE spirit. The 
use of a wide range of previous achievements within this field allows a holistic study and an observation of learning processes. It indicates what categories should be highlighted in explaining and studying the outcomes. The effect of the study's analysis is a designed tool, which enables the arrangement of the data acquired during the studies. That launch comparative studies related not only to the skills, but also the content provided by AOE programs, theories as well as methods used to achieve their objectives. It also allows evolving international standards of competences analyzing, applicable in various programs such as the Train of Trainers courses. In the paper an attempt has been undertaken to use a developed tool on the example of own educational processes, to gain practical knowledge of applicability before using in future groundwork materials analyze.

The ultimate division of categories into soft and hard competencies and skills together with taxonomy considering outcomes from a cognitive, psychomotor and affective perspective enabled the inspection of the profile of an AOE program participant, comparing these profiles during the next stage of research. Moreover, this paper serves as a fair confirmation of the holistic and effective nature of AOE teaching and learning methods.

This article is part of an internal grant nr 0420/2341/17 at the Faculty of Historical and Pedagogical Sciences of the University of Wrocław, Institute of Pedagogy.

\section{REFERENCES}

[1] Bloom, B., Engelhart, M., Furst, E., Hill, W., \& Krathwohl. D. (1956). Taxonomy of educational objectives: The classification of educational goals. New York: Longmans Green.

[2] Ewert, A. (1989). Outdoor Adventure Pursuits: Foundations, models and theories. Columbus: Horizons Publishing.

[3] Ewert, A., \& Sibthorp J. (2014). Outdoor Adventure Education. Foundations, Theory, and Research Champaign: Human Kinetics.

[4] Gelter H. (2000). Friluftsliv: The Scandinavian Philosophy of Outdoor Life. Canadian Journal of Environmental Education, 1(5). 77-92.

[5] Goldenberg, M., Soule, K., Cummings, J., \& Pronsolino, D. (2010). Longitudinal participant outcomes associated with Outward Bound National Outdoor Leadership School: A means end investigation. Research of Outdoor Education, 10. 57-73.

[6] Hattie, J., Marsh, H., Neill, J., \& Richards G. (1997). Adventure Education and Outward Bound: Out-of-class experiences that make a lasting difference. Review of Educational Research, 67(1). 43-87.

[7] Kellert, S. (1998). A national study of outdoor wilderness experience. Washington: Island Press.

[8] Kraiger, K., Ford J., \& Salas E. (1993). Application of cognitive, skill based, and affective theories of learning outcomes to new methods of training evaluation. Journal of Applied Psycho$\log y, 78(2)$. 311-328.

[9] Miles, J. C., \& Priest, S. (Eds.) (1990). Adventure Education, State Collage: Venture Publishing.

[10] Norling, J., \& Sibthorp J. (2006). A survey of experiential education outcomes and evaluation strategies: Reanalysis and condensed reporting. Horizons, July. 14-18.

[11] Rickinson, M., Dillon, J., Teamey, K., Morris, M., Choi, M., Sanders, D., \& Benefield, P. (2004). A review of research on outdoor learning. Shrewsbury: National Foundation for Educational Research and King's College London. 
[12] Ritson, L. (2016). Adventure Education. Fun games and activities for children and young people. New York: Routledge.

[13] Rubens, D. (1997). Outdoor Education, Adventure and Learning - a Fusion. Edinburgh: Msc Education Degree University of Edinburgh.

[14] Sipthorp, J., Furmann, N., Paisley, K.,Schumann, S., \& Gookin, J. (2011). Mechanisms of learning transfer in adventure education: Qualitative results from the NOLS transfer survey. Journal of Experimental Education, 34(2). 109-118.

[15] Sibthorp, J., Pisley, K., Furman, N., \& Gookin, J. (2008). Long-term impacts attributed to participation in adventure education: Preliminary findings from NOLS. Research in Outdoor Education, 9. 86-102. 